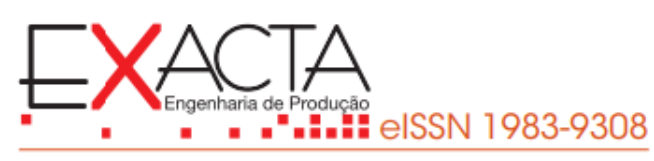

\title{
CAC-REDES: CONCEPÇÃO E APLICAÇÃO AO ESTUDO DA COMPETIÇÃO ENTRE EMPRESAS DO CLUSTER VITIVINICULTOR DE SÃO ROQUE
}

\author{
CAC-REDES: CONCEPTION AND APPLICATION TO THE STUDY OF THE \\ COMPETITION BETWEEN COMPANIES OF THE SÃO ROQUE VITIVINICULTURE \\ CLUSTER
}

Versão do autor aceita publicada online: $13 \mathrm{fev} .2020$

Publicado online: 12 maio 2021

Como citar esse artigo - American Psychological Association (APA):

Gonçalves, R. G., Contador, J. C., Contador, J. L., Satyro, W. C., \& Florêncio, C. A. de D. (2021, abr./jun.). CAC-Redes: concepção e aplicação ao estudo da competição entre empresas do cluster vitivinicultor de São Roque. Exacta, 19(2), 226-250.

https://doi.org/10.5585/exactaep.2021.14197.

Submeta seu artigo para este periódico $\beta$

Dados Crossmark 


\title{
CAC-REDES: CONCEPÇÃO E APLICAÇÃO AO ESTUDO DA COMPETIÇÃO ENTRE EMPRESAS DO CLUSTER VITIVINICULTOR DE SÃO ROQUE
}

\author{
CAC-REDES: CONCEPTION AND APPLICATION TO THE STUDY OF THE \\ COMPETITION BETWEEN COMPANIES OF THE SÃO ROQUE VITIVINICULTURE \\ CLUSTER
}

\author{
iD Rubens Gomes Gonçalves ${ }^{1}$ \\ ID José Celso Contador ${ }^{2}$ \\ (iD) Jose Luiz Contador ${ }^{3}$ \\ (iD) Walter Cardoso Satyro ${ }^{4}$ \\ iD Carlos Alberto de Domenico Florêncio ${ }^{5}$
}

\author{
${ }^{1}$ Mestre (M.Sc.) \\ Universidade Paulista (UNIP) \\ rubenslpgo@gmail.com \\ 2 Doutor - Livre docente \\ Universidade Paulista (UNIP) \\ celsocontador@terra.com.br \\ ${ }^{3}$ Doutor - Livre docente \\ Universidade Estadual Paulista (UNESP) \\ jose.contador@unesp.br \\ ${ }^{4}$ Doutor \\ Universidade Nove de Julho (UNINOVE) \\ satyro.walter@gmail.com \\ ${ }^{5}$ Mestre (M.Sc.) \\ Universidade Paulista (UNIP) \\ cfloren@terra.com.br
}

Recebido em: 12 jun. 2019

Aprovado em: 13 fev. 2020
Resumo: Qual a influência das competências organizacionais e dos vínculos sociais na competitividade das empresas que operam em rede de negócio? Essa é a pergunta central do novo modelo de campos e armas da competição aplicado a rede de negócios (CAC-Redes), em desenvolvimento por Contador, que integra num todo coerente três perspectivas: Visão Baseada na Indústria, RBV e Visão Relacional considerando simultaneamente a posição competitiva da empresa, suas competências e seus vínculos sociais. A concepção do CAC-Redes é aqui apresentada ineditamente. A pesquisa de campo adotou o método hipotético-dedutivo proposto por Popper para corroborar as hipóteses estatísticas provenientes do CAC-Redes. Duas são suas principais contribuições, que justificam sua importância: preencher lacuna teórica, pois há poucos estudos relacionando competência organizacional e vínculos sociais com vantagem competitiva das empresas, e subsidiar o desenvolvimento e futura validação do CAC-Redes.

Palavras-chave: Competitividade. Campos e armas da competição. Vínculos sociais. Cluster. Vinícolas.

Abstract: What is the influence of organizational competencies and social ties on the competitiveness of companies operating in a business network? This is the central question of the CAC-Redes (Fields and Weapons of Competition Model applied to business networks), developed by Contador, which integrates into a coherent whole three perspectives: Industry-Based Vision, RBV and Relational View simultaneously considering the company's competitive position, its competencies and its social ties. The design of the CAC-Redes is presented here unpublished. This study adopted the hypothetic-deductive method proposed by Popper to corroborate the statistical hypotheses coming from CAC-Redes. The main contribution are two, which justify its importance: to fill a theoretical gap, since there are few studies relating organizational competence and social ties with competitive advantage of the companies, and to subsidize the development and future validation of CAC-Redes.

Keywords: Competitiveness. Fields and weapons of competition. Social ties. Cluster. Wineries. 


\section{Introdução}

Contador (2008) concebeu, desenvolveu e validou o modelo de campos e armas da competição (CAC), modelo qualiquantitativo que representa como as empresas concorrentes competem. Ele fundamenta-se em duas perspectivas: Visão Baseada na Indústria - VBI - (ou Organização Industrial), que defende serem os fatores da indústria e a orientação para o mercado os determinantes primários do desempenho empresarial (Bain, 1968; Caves \& Porter, 1977; Porter, 1980, 1985, 1996); e ResourceBased View (RBV), que defende serem o ambiente interno e os recursos da firma os impulsionadores da vantagem competitiva (Barney et al., 2001; Hoopes et al., 2003; Ramos-Rodríguez e Ruíz-Navarro, 2004)

Os dois constructos centrais do CAC exprimem essas perspectivas: campo da competição reflete a VBI, e arma da competição, a RBV. Campo da competição representa um atributo do produto ou da empresa reconhecível e valorizável pelo cliente, como preço, qualidade do produto, prazo (existem 14 campos da competição). Arma da competição é uma atividade ou recurso da empresa capaz de lhe gerar vantagem competitiva, como processo produtivo (de bens e/ou serviços), canais de acesso à empresa, sistema de materiais, análise da concorrência, publicidade (uma empresa utiliza dezenas de armas da competição).

O CAC possui sete variáveis quantitativas, que medem, por exemplo, grau de competitividade, poderio competitivo da empresa, intensidade da capacidade de uma arma em gerar vantagem competitiva, relações entre armas e campos. Para validar o CAC, Contador (2008, p.139) confirmou hipóteses estatísticas baseadas nessas variáveis em pesquisas detalhadas envolvendo 176 empresas de seis segmentos industriais e seis de serviços, de 1999 a 2007.

Essas características qualitativas e quantitativas tornam o CAC o mais completo modelo de formulação de estratégia entre os 15 existentes (Satyro et al., 2017).

Agora, Contador (2018) está desenvolvendo um novo modelo qualiquantitativo, o de campos e armas da competição aplicado a redes de negócio (CAC-Redes), que é uma extensão do CAC. Ele se fundamenta nas duas perspectivas anteriores acrescidas da Visão Relacional (Dyer e Singh, 1998; Dyer et al., 2018), que defende serem a rede da empresa e as relações interempresariais geradoras de vantagem competitiva. Esta perspectiva é refletida pelo constructo vínculo da competição. De forma simplificada, o CAC-Redes é o CAC acrescido de vínculos econômicos, sociais e locacionais.

A maioria dos estudos sobre redes de negócio concentra-se nas relações entre os atores, sem considerar as competências empresariais, como estabelece a Visão Relacional. Mas, para estudar a vantagem competitiva das empresas que operam numa rede de negócio, Contador (2018) entende ser necessário considerar também suas competências. 
As considerações anteriores suscitam quatro questões relacionadas a empresas que operam em rede de negócio: a) as competências das empresas influenciam sua competitividade?; b) os vínculos sociais que desenvolvem com outros atores da rede influenciam sua competitividade?; c) apenas coopetição (competição e cooperação) é suficiente para ampliar sua competitividade?; d) quais vínculos sociais influenciam a competitividade? Essas questões motivaram a pesquisa, pois elas são fundamentais para o desenvolvimento do CAC-Redes.

O objetivo deste artigo é apresentar ineditamente a concepção do CAC-Redes (Contador, 2018). Adicionalmente, estão relatados os resultados da primeira pesquisa empírica realizada, importante porque contribuiu para o desenvolvimento desse novo modelo de competitividade em rede de negócio.

A motivação para o desenvolvimento do CAC-Redes centra-se no problema da pesquisa: Qual a influência das competências organizacionais e dos vínculos sociais na competitividade das empresas que operam numa rede de negócio? Decorre desse problema a hipótese geral do CAC-Redes: Numa rede de negócio, quanto maior a intensidade das competências de uma empresa e dos vínculos sociais que estabelece com as empresas concorrentes, maior sua competitividade em relação às concorrentes.

A pesquisa empírica usou o cluster vitivinicultor de São Roque apenas para testar essa hipótese geral, que foi confirmada por meio de três hipóteses específicas, verificadas por nove testes estatísticos.

O problema da pesquisa, ao considerar a influência simultânea dos vínculos sociais e competências na competitividade empresarial, permitiu suprir algumas lacunas da literatura, evidenciadas na Conclusão.

O cluster vitivinicultor de São Roque, localizado próximo a São Paulo, abriga empresas com habilidades e competências distintas. Foi escolhido por duas razões: a) importância econômica desse segmento; b) ser intensa a competição na vitivinicultura, permitindo estudar a competição intracluster.

Embora existam vários estudos sobre clusters e sobre competitividade, pesquisas que integrem esses dois assuntos são escassas. Assim, esta pesquisa contribui para o entendimento de como as empresas num cluster podem aumentar seu desempenho e obter vantagem competitiva. Esse desempenho, aqui denominado grau de competitividade, foi medido pela participação de mercado, mas garantida rentabilidade satisfatória.

O artigo destina-se a pesquisadores em competitividade e competição em redes de negócio, pois apresenta abordagem inédita e contribui para preencher algumas lacunas da literatura. Destina-se também a formuladores de estratégia empresarial.

\section{Revisão da literatura}

A pesquisa bibliográfica para a revisão utilizou as bases Scopus, Web of Science, Google Scholar e Scielo sobre os temas abordados. 


\subsection{Estratégia e vantagem competitiva em rede de negócio}

A ideia precursora de que competição e cooperação simultâneas podem gerar vantagens sustentáveis vem da obra clássica Princípios de Economia, de Alfred Marshall (1982, primeira edição de 1890), que abordou pioneiramente a concentração de indústrias especializadas em certas localidades, mostrando que a aglomeração poderia ajudar as empresas, particularmente as pequenas, a obter vantagens, chamadas de "economias externas marshallianas".

Realmente, Jarillo (1988) afirma que, paralelamente à aceitação teórica da importância da concorrência para formular a estratégia, é crescente a percepção de que o comportamento cooperativo intraempresarial está na raiz de muitas histórias de sucesso. Se uma empresa é capaz de construir um arranjo pelo qual terceiriza suas atividades para o mais eficiente fornecedor, mantém para si atividades que tem vantagem comparativa e reduz os custos de transações, um modo superior de organização emerge: a rede estratégica. Ela pode ser sustentável porque vínculos de longo prazo geram confiança, reduzem os custo das transações e, juntos com comprometimento e cooperação, criam valor em redes (Corte; Gaudio, 2014), valor que será ampliado se houver aprendizagem (Wang; Rajagopalan, 2015).

A posição das empresas na rede é outro elemento importante da competição, dado que a competição é mais intensa entre os atores que ocupam uma posição semelhante à de outros, mas é mitigada se os atores estiverem ligados entre si (Garcia-Pont e Nohria, 2002; Zaheer e Zaheer, 1999).

Assim, pela RBV, a rede de relacionamentos da empresa é fonte importante para a criação dos recursos inimitáveis geradores de valor e também permite enfrentar o desafio da imitação com o decorrer do tempo (Balestrin, Verschoore e Perucia, 2014). Como esses recursos são idiossincráticos, gerados por uma combinação única de redes que a empresa possui, são relativamente inimitáveis e insubstituíveis. Assim juntos, as redes da empresa e os seus recursos permitem que a empresa inicial sirva como uma fonte de vantagem competitiva sustentável (Gulati e Lawrence, 1997; Furrer et al., 2008)

Saber se uma empresa deve fazer ou comprar tem longa história na literatura estratégica (Gulati et al., 2000). A questão make-or-buy é fortemente influenciada pelo custo de transação, pois os riscos de contratação são inerentes a qualquer tipo de transação (Williamson, 1981).

As ligações da rede permitem que potenciais parceiros identifiquem e aprendam suas capacidades uns com os outros e também podem facilitar a due diligence de modo que cada parceiro tenha maior conhecimento sobre recursos e capacidades e maior confiança no outro nas suas avaliações mútuas (Gulati, 1995). As redes também podem atenuar o oportunismo, pois tornam mais provável que tais comportamentos sejam descobertos e se espalhem rapidamente na rede (Gulati et al., 2000).

Porter (1990), ao revelar que, em aproximadamente metade dos produtos pesquisados, a vantagem competitiva não era de nações, mas de cidades ou regiões que sediavam agrupamentos de 
empresas, deixou claro que a vantagem não era devido às empresas individualmente, mas sim, ao agrupamento existente (cluster).

Tal ponto de vista coincide com o de Zaccarelli et al. (2008): as empresas que possuem negócios entre si e se dedicam a determinado tipo de produto passam a ter, no seu conjunto, um poder de competir muito maior do que as empresas consideradas isoladamente.

A concorrência acirrada vem exigindo das empresas novas formas de atuar estrategicamente, $\mathrm{e}$ a formação de redes tem sido uma alternativa recorrente para melhorar sua competitividade. Formular estratégias competitivas é fundamental para a competitividade organizacional, já que são essenciais para as organizações obterem uma posição lucrativa no mercado (Porter, 1999).

\subsection{Competição e cooperação entre as empresas que operam em rede de negócio}

Para os economistas, a confiança implica propensão a cooperar - onde há confiança prévia, há comportamento cooperativo (La Porta et al., 1997).

A cooperação entre empresa pode ser motivada pela competição com uma terceira empresa (Bengtsson \& Kock, 1999). Assim, a cooperação pode decorrer da competição, mas, se tomada isoladamente, apesar de aumentar a competitividade (Rosenfeld, 1996), não deve sustentar um desempenho superior àquele proporcionado pelo equilíbrio das estratégias de cooperação e de competição (Boyd et al., 1997; Porter, 1998; Hoffmann et al., 2017).

As empresas não apenas cooperam entre si para partilhar conhecimento, como também competem entre si para maximizar seus próprios benefícios (Tsai, 2002). A cooperação e a competição simultâneas podem estimular grande compartilhamento de conhecimento, progresso tecnológico e expansão do mercado (Boyd et al., 1997; Hoffmann et al., 2017) e manter e melhorar os recursos que já possuem (Zonta et al., 2015). Para designar o balanceamento de situações de cooperação e competição simultâneas, criou-se o termo coopetição, que não é novo, pois se baseia na teoria dos jogos da década de 1950 (Nalebuff e Bradenburger, 1997). E as estratégias empresariais baseadas na competição e cooperação são capazes de gerar vantagem competitiva (Lee, Kim \& Kim, 2014; Martins, Rossoni, Duarte \& Martins, 2017; Zhang \& Wang, 2018).

A necessidade de recursos complementares é motor importante da cooperação interorganizacional (Richardson, 1972) e, por ela, as empresas não somente aprendem, mas também podem desenvolver a "confiança baseada no conhecimento" (Shapiro et al., 1992).

\subsection{CAC: modelo de campos e armas da competição}

Como o CAC-Redes (Contador, 2018) é uma extensão do CAC - modelo de campos e armas da competição (Contador, 2008). Para entender o CAC-Redes, é necessário explicitar os conceitos, 
constructos, variáveis qualitativas e quantitativas do CAC, que é um modelo que serve para estudar a competição empresarial com abordagem econômica.

O CAC tem uma tese que orientou sua concepção e desenvolvimento e sobre a qual ele se fundamenta (Contador, 2008, p.109):

Tese do CAC: Para a empresa ser competitiva, não há condição mais relevante do que ter alto desempenho apenas naquelas poucas armas que lhe dão vantagem competitiva nos campos da competição escolhidos para cada par produto/mercado.

Para entendê-la, é necessário conhecer seus constructos.

Dois são seus constructos qualitativos: campo da competição e arma da competição.

Campo da competição é o locus imaginário da disputa num mercado entre produtos ou entre empresas pela preferência do cliente, onde a empresa busca alcançar e manter vantagem competitiva, como preço e qualidade do produto, e representa um atributo do produto ou da empresa valorizado e de interesse do cliente. Campo coadjuvante é o locus imaginário secundário e complementar da disputa entre empresas pela preferência do cliente ao produto e/ou à empresa que complementa os campos da competição na definição da estratégia competitiva de negócio e representa também um atributo do produto ou da empresa valorizado e de interesse do cliente. (Contador, 2008, p.55;62).

Contador (2008, p.57) identificou 14 campos da competição(e coadjuvantes), que representam as maneiras básicas de a empresa se diferenciar por meio das características de seu produto e/ou da própria empresa, agregados em cinco macrocampos: macrocompetição em preço, produto, atendimento, prazo e imagem (Quadro 1).

\begin{tabular}{|c|c|}
\hline $\begin{array}{l}\text { Competição em preço } \\
\text { Preço propriamente dito } \\
\text { Condições de pagamento } \\
\text { Prêmio e/ou promoção }\end{array}$ & $\begin{array}{l}\text { Competição em prazo } \\
\text { Prazo de entrega do produto } \\
\text { Prazo de atendimento }\end{array}$ \\
\hline $\begin{array}{l}\text { Competição em produto (bem ou serviço) } \\
\text { Projeto do produto } \\
\text { Qualidade do produto } \\
\text { Diversidade de produtos }\end{array}$ & $\begin{array}{l}\text { Competição em imagem } \\
\text { do produto e da marca } \\
\text { de empresa confiável } \\
\text { em responsabilidade social (nos aspectos } \\
\text { preservacionista e cívico) }\end{array}$ \\
\hline $\begin{array}{l}\text { Competição em atendimento } \\
\text { Acesso ao atendimento } \\
\text { Projeto do atendimento } \\
\text { Qualidade do atendimento }\end{array}$ & \\
\hline
\end{tabular}

Um conjunto de um ou dois campos da competição e de um ou dois coadjuvantes retrata a estratégia competitiva de negócio e representa a estratégia de posicionamento do produto no mercado. 
É pela escolha de diferentes campos da competição e coadjuvantes que as empresas se diferenciam. (Contador, 2008, p.69).

Arma da competição é qualquer atividade executada ou recurso administrado por um grupo de funcionários com atribuições homogêneas utilizado pela empresa para conquistar e/ou manter vantagem competitiva, como propaganda, tecnologia da informação, automação do processo produtivo. Ou seja, as armas da competição representam as competências organizacionais. A origem da vantagem competitiva está nas armas da competição. Uma mesma arma serve para competir em mais de um campo e, para competir em um campo, são necessárias várias armas (Contador, 2018, p.78).

Relevância de armas. As armas da competição são classificadas, segundo sua importância para propiciar vantagem competitiva, em armas relevantes, semirrelevantes e irrelevantes. Uma arma de qualquer dessas três classes pertence ao conjunto das armas da competição da empresa. Arma relevante é aquela que proporciona elevada vantagem competitiva a empresa no campo escolhido para competir. Arma semirrelevante é aquela que proporciona moderada vantagem competitiva no seu campo da competição. E irrelevante é aquela que não propicia vantagem competitiva, nem no campo da competição, nem no coadjuvante (Contador, 2018).

Essa classificação é feita pela matriz de priorização das armas junto com o Índice de Nihans (N). Este índice, utilizado para classificar um conjunto homogêneo de itens quantificados, é dado por:

$$
N=\frac{\sum^{\prime}(s p)^{2}}{\sum(s p)}
$$

Nessa expressão, (sp) é a soma dos pesos de cada linha da matriz de priorização, que reflete a importância de cada arma para proporcionar vantagem competitiva no campo da competição analisado. Armas cujo $\mathrm{sp}>\mathrm{N}$ pertencem à classe $\mathrm{A}$ (relevantes); $\mathrm{sp}<\mathrm{N}$, à classe não-A. Aplicando novamente $\mathrm{o}$ índice de Nihans à classe não-A, obtém-se novo valor de $\mathrm{N}$ e, daí, armas cujo $\mathrm{sp}>\mathrm{N}$ pertencem à classe $B$ (semirrelevantes); e sp < N, à classe C (irrelevantes) (Contador, 2008, p.91).

\subsection{As variáveis quantitativas do CAC}

O CAC possui cinco principais variáveis quantitativas: a) grau de competitividade; b) intensidade da arma; c) intensidade média das armas; d) foco das armas no campo da competição; e) dispersão das armas no campo da competição.

Competitividade é a capacidade da empresa em obter resultado sustentável superior ao das concorrentes, resultado medido por um indicador de crescimento de mercado, assegurada uma 
rentabilidade satisfatória, por meio do alcance de uma ou mais vantagens competitivas, ou seja, é a capacidade da empresa obter vantagem competitiva.

Grau de competitividade da empresa é a medida da competitividade de uma empresa em relação a um conjunto de empresas concorrentes.

Competir num campo significa ser, ou almejar ser, melhor que as concorrentes nesse campo da competição.

Intensidade da arma é o grau de intensidade com que cada arma é utilizada pela empresa, avaliada em cinco níveis (0 a 5); é a potência e alcance de uma arma.

Intensidade média das armas (IMA) é a média aritmética da intensidade de todas as armas da competição da empresa.

Foco das armas, o mesmo que foco das armas da competição nos campos da competição e coadjuvantes que representam a estratégia competitiva de negócio da empresa, é a variável quantitativa que mede a aplicação de esforços nas armas da competição que proporcionam vantagem competitiva num campo da competição ou coadjuvante. O foco das armas expressa quantitativamente a tese do CAC e mede a aplicação de esforços nas armas relevantes para um campo da competição ou coadjuvante. O foco das armas é calculado pelo quociente entre a soma da intensidade das armas relevantes e a soma da intensidade máxima possível de ser obtida em tais armas. Sendo a média de muitas variáveis aleatórias, é uma variável com distribuição normal de probabilidades, portanto contínua, com domínio entre 0 e 1.

Dispersão das armas, o mesmo que dispersão das armas da competição nos campos da competição e coadjuvantes que representam a estratégia competitiva de negócio da empresa, é a variável quantitativa que mede a aplicação de esforços nas armas da competição que não proporcionam vantagem competitiva num campo da competição ou coadjuvante, ou seja, mede a aplicação de esforços nas armas irrelevantes para um campo da competição ou coadjuvante. É calculada de forma análoga ao foco das armas, considerando as armas irrelevantes (o foco considera as relevantes). A dispersão das armas serve de contraprova: deve haver associação positiva entre o foco e o grau de competitividade e não deve haver associação entre dispersão e grau de competitividade.

\section{CAC-Redes: modelo de campos e armas da competição aplicado a rede de negócios}

O CAC-Redes, uma extensão do CAC para aplicação em rede de negócio, é um modelo que serve para estudar a competição entre empresas do mesmo segmento econômico que operam numa rede de negócio, cuja abordagem é socioeconômica. É importante ressaltar que essa abordagem difere das mais 
frequentemente estudadas sobre redes, que ora enfatizam as relações entre atores, ora enfatizam a competição entre redes ou com empresas extrarrede. O CAC-Redes pretende integrar todos esses fatores (Contador, 2018).

O CAC-Redes tem uma tese que orienta sua concepção e desenvolvimento e sobre a qual ele se fundamenta. Mas essa tese precisa ainda ser corroborada. Ela é similar à tese do CAC (Contador, 2008, p.109), acrescentando os vínculos citados:

Tese do CAC-Redes: Para a empresa que opera numa rede de negócio ser competitiva, não há condição mais relevante do que ter alto desempenho apenas naquelas poucas armas e apenas naqueles poucos vínculos que Ihe dão vantagem competitiva nos dos campos da competição e coadjuvantes escolhidos para cada par produto/mercado.

Para entendê-la, é necessário conhecer seus constructos.

Três são seus constructos qualitativos: campo da competição, arma da competição e vínculo da competição (Contador, 2018). Os dois primeiros já foram apresentados na seção anterior sobre o CAC.

Vínculo da competição é qualquer conexão da empresa com os componentes da rede utilizada por ela para conquistar e/ou manter vantagem competitiva. Ele evidencia a capacidade que os componentes conectados (fornecedores, concorrentes, clientes, outros componentes do microambiente e elementos do território físico) possuem para influenciar a vantagem competitiva da empresa. (Contador, 2018).

Os vínculos são de três naturezas: a) sociais (confiança, comprometimento e cooperação); b) econômicos (relacionados aos recursos e capacidades dos fornecedores e dos outros componentes e relacionados às necessidades, preferências e anseios dos seus clientes); e c) locacionais (relacionados aos elementos do território físico). Esta pesquisa considerou unicamente os vínculos sociais.

Como no CAC, um mesmo vínculo da competição serve para competir em mais de um campo e, para competir em um campo, são necessárias vários vínculos da competição (Contador, 2018). Relevância dos vínculos. Os vínculos da competição são classificados, segundo sua importância para propiciar vantagem competitiva, em relevantes, semirrelevantes e irrelevantes, cujos conceitos são idênticos aos das armas, sendo essa classificação feita também por uma matriz de priorização junto com o Índice de Nihans (Contador, 2018). 


\subsection{As variáveis quantitativas do CAC-Redes}

Além das cinco principais variáveis quantitativas do CAC, o CAC-Redes possui mais sete: a) intensidade do vínculo; b) intensidade média dos vínculos; c) intensidade média das armas e vínculos; d) foco dos vínculos da competição; e) foco das armas e vínculos da competição; f) dispersão dos vínculos da competição; e g) dispersão das armas e vínculos da competição, cujos conceitos são similares aos do CAC (Contador, 2018).

Intensidade do vínculo é a intensidade com que a empresa aproveita a capacidade que o componente conectado possui para conquistar e/ou manter vantagem competitiva, avaliada em cinco níveis ( 0 a 5).

Intensidade média dos vínculos (IMV) é a média aritmética da intensidade de todos os vínculos da competição da empresa (os relevantes, os semirrelevantes e os irrelevantes).

Intensidade média das armas e vínculos (IMAV) é a média aritmética da intensidade de todas as armas e de todos os vínculos da competição da empresa (relevantes, semirrelevantes e irrelevantes).

Foco dos vínculos. Foco das armas e vínculos, Dispersão dos vínculos e Dispersão das armas e dos vínculos têm o mesmo conceito de foco e dispersão das armas da competição, aplicado respectivamente aos vínculos e às armas e vínculos. O foco das armas e vínculos expressa quantitativamente a tese do CAC-Redes.

\section{Metodologia}

Esta seção trata da metodologia da pesquisa empírica usada para testar no cluster vitivinicultor de São Roque a hipótese geral do CAC-Redes, que resultou do problema da pesquisa do CAC-Redes: Qual a influência das competências organizacionais e dos vínculos sociais na competitividade das empresas que operam numa rede de negócio?

Dos conceitos, constructos e tese do CAC-Redes e do problema de pesquisa, formulou-se a hipótese geral da pesquisa: Na rede de vitivinicultura de São Roque, quanto maior a intensidade das armas relevantes e quanto maior a intensidade dos vínculos sociais relevantes, maior sua competitividade em relação às concorrentes. Entenda-se que armas relevantes e vínculos relevantes significam serem relevantes aos campos da competição e coadjuvantes escolhidos pela empresa para competir (e que representam sua estratégia competitiva e geral a variável foco).

Para validar a tese do CAC, Contador $(2008$, p.117) criou as variáveis quantitativas: grau de competitividade, foco das armas no campo da competição, dispersão das armas no campo da competição e intensidade média das armas. A tese é mensurada pelo foco das armas no campo da 
competição - para ela ser válida, é necessário: a) haver associação forte do foco com o grau de competitividade (GC) da empresa; b) não haver associação da dispersão das armas com o GC, pois a dispersão tem a mesma natureza do foco, mas calculada sobre as armas irrelevantes aos campos escolhidos pela empresa para competir (o foco é calculado sobre as armas relevantes); e c) haver associação fraca ou moderada da intensidade média das armas com o GC, pois ela é calculada sobre todas as armas da competição (o foco é calculado apenas sobre as relevantes). Ou seja, as variáveis dispersão e intensidade média das armas servem de contraprova. Como essas três hipóteses foram confirmadas pelas pesquisas de Contador (Contador, 2008, p. 139), a tese foi validada.

Sobre essas considerações e a hipótese geral do CAC-Redes, foram formuladas três hipóteses específicas da pesquisa no cluster vitivinicultor de São Roque, mostradas no Quadro 2.

Quadro 2 - Hipóteses específicas sobre a influência da estratégia competitiva operacional na competitividade das empresas que operam numa rede de negócio

Hipóteses específicas

Hipótese específica 1: O foco das armas e vínculos da competição nos campos da competição e coadjuvantes eleitos pela empresa tem forte influência na sua competitividade em relação às empresas concorrentes.

Hipótese específica 2: A dispersão das armas e vínculos da competição nos campos da competição e coadjuvantes eleitos pela empresa não influencia sua competitividade em relação às empresas concorrentes.

Hipótese específica 3: A intensidade média das armas e vínculos da competição da empresa tem pequena influência na sua competitividade em relação às empresas concorrentes.

Fonte: Contador (2018).

As hipóteses específicas relativas ao cluster vitivinicultor de São Roque foram testadas por meio da correlação linear de Pearson.

O estudo foi feito para o par produto/mercado: vinho tinto de mesa / São Roque e São Paulo.

Quanto à abordagem, esta pesquisa se caracteriza como um estudo qualiquantitativo.

O método adotado é o hipotético-dedutivo proposto por Popper (2005), pois segundo Daniel Moreira (2002):

[...] os estudos de campo quantitativos guiam-se pelo método conhecido como hipotético-dedutivo. Esse método diz o seguinte: o pesquisador parte de quadros conceituais de referência tão bem estruturados quanto possível, a partir do qual formula hipóteses sobre os fenômenos e situações que se quer estudar. Uma lista de consequências é então deduzida das hipóteses. [...] Os dados são analisados com apoio de Estatística ou outras técnicas matemáticas. Os tradicionais levantamentos amostrais de dados (surveys) com questionários fechados e escalas de medida são exemplos clássicos de estudos de campo quantitativos [...] (MOREIRA, 2002). 
O método hipotético-dedutivo inicia pela existência de um problema, acerca do qual são formuladas hipóteses que o explicam preliminarmente. Enquanto o método dedutivo procura confirmar a hipótese, o hipotético-dedutivo procura evidências empíricas para derrubá-la. Esse método possui três momentos: (1) problema; (2) solução proposta consistindo em uma conjectura; e (3) testes de falseamento: tentativas de refutação, entre outros meios, pela observação e experimentação. Se a hipótese superar os testes rigorosos, estará corroborada, confirmada provisoriamente, não definitivamente como querem os indutivistas (Marconi e Lakatos, 2003).

O método popperiano é recomendável para a pesquisa, pois se pretende corroborar a hipótese geral.

O procedimento de pesquisa do tipo survey (Fonseca, 2002).

O estudo cumpriu as seguintes etapas:

1a) Formulação do problema de pesquisa e das hipóteses geral e específicas e definição dos respectivos testes estatísticos.

2a) Obtenção de informações: entrevistas com alguns proprietários formadores de opinião para obter informações sobre a realidade local e possibilitar a elaboração dos questionários, principalmente sobre as armas da competição típicas desse setor; acesso a fontes secundárias; participação em eventos e palestras realizados no âmbito do cluster; e acesso a diversos sites sobre a vitivinicultura.

3a) Elaboração de quatro questionários para coletar em cada vinícola: a) informações gerais; b) identificação de três campos, um da competição e dois coadjuvantes, nos quais cada vinícola almeja obter vantagem competitiva; c) avaliação da intensidade de cada uma das 53 armas da competição; d) avaliação da intensidade dos 18 vínculos sociais (confiança, comprometimento e cooperação).

4a) Aplicação dos questionários por meio de entrevistas pessoais com os proprietários ou gerentes do universo de 13 vinícolas.

5a) Processamento dos dados coletados para calcular as 12 variáveis quantitativas do CACRedes e os coeficientes de correlação linear de Pearson.

6a) Análise dos resultados da pesquisa e verificação das hipóteses.

\section{Resultados e discussão}

A pesquisa buscou responder ao problema: Qual a influência das competências organizacionais e dos vínculos sociais na competitividade das empresas que operam na rede de negócio de vitivinicultura de São Roque? Para respondê-lo, utilizaram-se dados obtidos nas 13 vinícolas existentes. Apesar de a 
amostra ser pequena, pode-se considerar praticamente normal a distribuição amostral, o que permite aplicar os testes estatísticos previstos (Costa Neto, 2002).

\subsection{Descrição da rede de negócio de vitivinicultura de São Roque (SP)}

Um dos achados da pesquisa foi verificar que a rede possui empresas em diferentes estágios de empreendedorismo e tecnologias. As vinícolas recebem de 3 a 5 mil visitantes por fim de semana (Roteiro do Vinho) e muito mais nas festas e eventos comemorativos (como a Expo São Roque). Esse fluxo é devido à propaganda pelas diversas mídias e pelo "boca a boca"

Outro achado da pesquisa foi desmistificar o tabu de não existirem parreirais em São Roque, ocorrendo apenas o envase do vinho trazido em caminhões do Rio Grande do Sul com rótulos de cada vinícola. O perfil das empresas é bastante variado, pois embora algumas funcionem assim, ainda existem vinícolas com iniciativas diferenciadas, algumas poucas continuam com parreirais, e outras mantêm parte da produção a partir de uva comprada.

São empresas de origem familiar. É comum ouvir dos atuais proprietários: "Quando meu bisavô (ou avô) iniciou a vinícola [...]". Muitas se profissionalizaram, mas ainda são administradas pela família. Atualmente, existem 14 empresas (10 vinícolas, três adegas e uma destilaria) filiadas ao SINDUSVINHO (Sindicato da Indústria do Vinho de São Roque). Esse número já foi 120 nos anos 1960-1970.

A produção é comercializada no Roteiro do Vinho (venda balcão, com sommelier, ponto de degustação, gastronomia, lazer e enoturismo) e por distribuidores e varejistas (supermercados, empórios, bares, restaurantes e pizzarias). Uma vinícola vende grandes volumes para GPA/Extra, Wal Mart, Sonda e Carrefour. As vinícolas participam da Expo São Roque, Festa do Vinho e da Alcachofra e Festa da Vindima, que comemora a colheita da uva em janeiro, na qual é possível participar da "pisa" da uva. Algumas vinícolas fabricam vinhos finos da uva Lorena, variedade desenvolvida com apoio da Embrapa, que está adaptada ao Brasil quanto à brotação, poda verde e poda seca. O terroir é analisado (adaptação da uva ao solo, clima e metodologias usadas no plantio e cultivo do vinhedo).

Um dos depoimentos colhidos nas entrevistas é esclarecedor: o consumo de vinho no Brasil é da ordem de 1,8 litros/habitante-ano, e na Europa, 50 litros/habitante-ano. É preciso triplicar o consumo brasileiro para atingir 10\% do europeu, e os desafios são enormes, exigindo cooperação para suplantá-los, como: a) fomentar o consumo de vinho entre os brasileiros, em especial o de procedência nacional; b) melhorar a qualidade do vinho local e nacional; c) aumentar a produção, pois se o consumo per capita duplicar, faltará vinho; e d) trabalhar em conjunto para obter produtos, subprodutos e serviços classe mundial e oferecê-los em São Roque. 
Um vinicultor de vinhos finos destacou que o consumidor busca experiências de consumo com coração e mente e, portanto, o vinho precisa ser visto pelo cliente como produto de alto valor agregado, e não mera commodity.

Outra vinícola fabrica vinhos Kasher apenas para a colônia judaica.

Outro achado da pesquisa, decorrente desses depoimentos, foi constatar a grande variedade de interesses, objetivos e estratégias dos vinhateiros de São Roque.

\subsection{Processamento dos dados coletados}

Para calcular o grau de competitividade das vinícolas (GC), adotou-se o período 2012 a 2015, pois algumas delas não dispunham de dados relativos a 2016. O GC de uma vinícola foi calculado dividindo a variação percentual da produção de vinho dessa vinícola pela variação percentual da produção de vinho do cluster e multiplicando o resultado por 100. Denominando por $V_{\text {it a }}$ produção de vinho da vinícola (i) no ano (t), e por $\mathrm{VT}_{\mathrm{t}}$ a produção total de vinho do cluster no ano (t), o GC da vinícola (i) é dado por:

$$
\mathrm{GC}_{\mathrm{i}}=\left[\left(\mathrm{V}_{\mathrm{i} 2015} / \mathrm{V}_{\mathrm{i2012}}\right) * 100\right] /\left(\mathrm{VT}_{2015} / \mathrm{VT}_{2012}\right)
$$

Essa expressão evidencia o crescimento da produção de vinho da vinícola (i) em relação ao crescimento da produção de vinho do cluster - GC maior que 100 significa que a vinícola cresceu mais que o conjunto das vinícolas do cluster. O GC das vinícolas está mostrado na Tabela 2.

Análise da amostra. Num estudo sobre competitividade empresarial, é necessário considerar apenas as empresas que são concorrentes, aquelas que Porter (1980) entende pertencentes à mesma indústria e que Contador (2008, p.64) entende serem do mesmo par produto/mercado. A destilaria e duas vinícolas, a V7 e V8, não se enquadram nessa categoria, pois são distribuidoras de vinhos e não produtoras. Portanto, é justificável excluí-las da amostra.

A análise da normalidade da amostra para realização dos testes de hipótese (correlação linear) constatou que os valores da variável normal reduzida (z) para três vinícolas são: V1 (1,91); V2 $(1,53)$; V5 $(-2,33)$, caracterizando pontos fora da normalidade estatística, explicados por fatores estranhos ao processo competitivo. Assim, elas foram excluídas da amostra para garantir a normalidade aos dados necessária aos testes estatísticos (Costa Neto, 2002, p. 85).

Portanto, a amostra final ficou constituída por oito vinícolas (V3; V4; V6; V9; V10; V11; V12 e V13).

Classificação das empresas em mais e em menos competitivas. Para classificar as vinícolas em mais e em menos competitivas, foi utilizado o citado Índice de Nihans (N) considerando o grau 
de competitividade (GC) de cada vinícola. Como $\mathrm{N}$ resultou 99,88, as empresas mais competitivas são aquelas cujo GC é superior a 99,88, e as menos competitivas, inferior a 99,88.

\subsection{Características do cluster de vinhos de São Roque}

Duas características marcantes descobertas na pesquisa merecem destaque:

1ํ) O fato de muitos dos empresários possuírem laços de parentesco e/ou terem crescidos juntos, se encontrarem nas escolas, festas, igreja e terem atividades de lazer em conjunto favorece a existência dos vínculos sociais de confiança, comprometimento e cooperação entre as vinícolas;

2ํ) O grande aglutinador entre elas é o roteiro do vinho, que faz com que as vinícolas se beneficiem de suas complementaridades (lazer, gastronomia e hospedagem). Isso maximiza o grau de satisfação do turista e diminui o custo de divulgação de suas atrações, pois o visitante tanto pode comprar vinhos e produtos típicos da região, apreciar um restaurante de cozinha típica portuguesa ou italiana, quanto hospedar-se numa pousada. O roteiro do vinho possui aproximadamente 10 quilômetros de via bem pavimentada e sinalização das atrações, que são bastante diversificadas. Interessante notar o uso da expressão "enoturismo" por parte dos empresários, o que inclui: visita à área de produção em algumas vinícolas, aos sábados, domingos e feriados; lojas, arquitetura e decoração cuidadosas; folders dos produtos; presença de sommeliers nos pontos de degustação; e até um museu.

\subsection{Campos da competição - estratégia competitiva de negócio}

Os campos da competição escolhidos pelas vinícolas, que representam sua estratégia competitiva de negócio, estão mostrados na Tabela 1. 
Tabela 1 - Campos da competição adotados pelas vinícolas

\begin{tabular}{|c|c|c|c|c|c|c|c|c|c|c|}
\hline $\begin{array}{l}\text { Campos da } \\
\text { Competição }\end{array}$ & V3 & V4 & V6 & V9 & V10 & V11 & V12 & V13 & $\begin{array}{l}\text { Total } \\
\text { (1우) }\end{array}$ & $\%(10)$ \\
\hline Projeto do produto & & 3음 & & & & & & & & \\
\hline Qualidade do produto & 10 & & 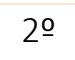 & 3 & 10 & & & 20 & 2 & 25,0 \\
\hline $\begin{array}{l}\text { Qualidade do } \\
\text { atendimento }\end{array}$ & & & & 10 & 20 & & 20 & & 1 & 12,5 \\
\hline $\begin{array}{l}\text { Acesso ao } \\
\text { atendimento }\end{array}$ & & 10 & & & & & & & 1 & 12,5 \\
\hline Preço & 30 & & 19 & & & & & 30 & 1 & 12,5 \\
\hline $\begin{array}{l}\text { Diversidade de } \\
\text { produtos }\end{array}$ & & & 3은 & & & 10 & & & 1 & 12,5 \\
\hline $\begin{array}{l}\text { Imagem produto e } \\
\text { marca }\end{array}$ & 2 & $2 \stackrel{0}{2}$ & & 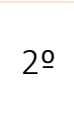 & 3은 & 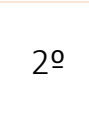 & 1 은 & 10 & 2 & 25,0 \\
\hline $\begin{array}{l}\text { Imagem empr. } \\
\text { confiável }\end{array}$ & & & & & & 3은 & $3 ㅇ$ & & & \\
\hline Total & & & & & & & & & 8 & 100 \\
\hline \multicolumn{11}{|c|}{ 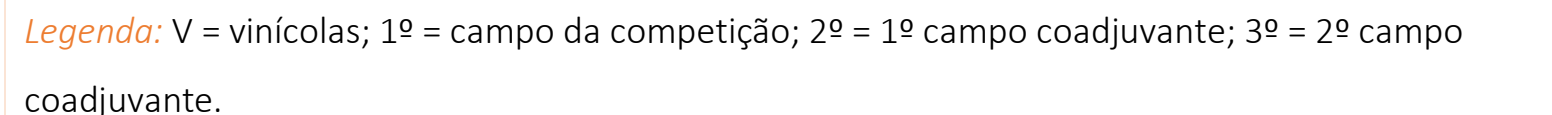 } \\
\hline
\end{tabular}

Fonte: Autores.

Um importante achado da pesquisa foi constatar a significativa diversidade da principal estratégia competitiva de negócio das vinícolas, representada pelo campo da competição (indicado por 1 ㅇ na Tabela 1): seis campos da competição foram escolhidos. Apenas qualidade do produto e imagem do produto e da marca foram escolhidos por duas vinícolas. Essa diversidade decorre da multiplicidade de interesses, objetivos, prioridades, segmentos de atuação e processos de fabricação.

Testes estatísticos. A Tabela 2 mostra o valor das nove variáveis quantitativas do CAC-Redes de cada vinícola. Na última linha está o coeficiente de correlação linear de Pearson (r) entre o grau de competitividade das vinícolas e os valores das respectivas variáveis. Nota-se que, quanto a armas, vínculos e armas + vínculos, o valor de (r) relativo ao foco é sempre superior aos valores de (r) relativos à intensidade média e à dispersão. Este é um importante resultado da pesquisa, pois confirma, provisoriamente (Popper, 2005), a tese do CAC-Redes. 
Tabela 2 - Resultados dos testes estatísticos

\begin{tabular}{|c|c|c|c|c|c|c|c|c|c|c|}
\hline \multicolumn{1}{|c|}{} & \multicolumn{3}{|c}{ Armas } & \multicolumn{3}{c|}{ Vínculos } & \multicolumn{3}{c|}{ Armas + Vínculos } \\
\hline Vinic. & GC & IMA & Foco & Dispersão & IMV & Foco & Dispersão & IM(A+V) & Foco & Dispersão \\
\hline V4 & 112,14 & 3,792 & 0,900 & 0,686 & 3,944 & 0,880 & 0,800 & 3,831 & 0,895 & 0,706 \\
\hline V10 & 107,66 & 3,642 & 0,750 & 0,737 & 4,167 & 0,840 & 0,943 & 3,775 & 0,771 & 0,792 \\
\hline V3 & 106,80 & 3,736 & 0,775 & 0,737 & 3,944 & 0,880 & 0,771 & 3,789 & 0,800 & 0,746 \\
\hline V12 & 99,68 & 3,132 & 0,667 & 0,600 & 3,667 & 0,767 & 0,800 & 3,268 & 0.692 & 0,646 \\
\hline V13 & 97,87 & 3,302 & 0.767 & 0,600 & 3,278 & 0,633 & 0,667 & 3,296 & 0,733 & 0,615 \\
\hline V11 & 89,71 & 3,132 & 0,663 & 0,642 & 3,444 & 0,560 & 0,778 & 3,197 & 0,600 & 0,638 \\
\hline V6 & 89,71 & 3,245 & 0,640 & 0,632 & 2,833 & 0,520 & 0,633 & 2,394 & 0,495 & 0,471 \\
\hline V9 & 89,71 & 2,245 & 0,486 & 0,436 & 3,056 & 0,480 & 0,657 & 3,211 & 0,638 & 0,686 \\
\hline
\end{tabular}

Fonte: Autores.

\subsection{Verificação das hipóteses}

Para interpretar os valores do coeficiente de correlação ( $r$ ), adotou-se a seguinte recomendação de Costa Neto (Contador, 2008, p.584): a) $r>0,900$ significa associação positiva muito forte; b) 0,800 <r<0,899, associação forte; c) 0,700 <r<0,799, associação moderada; d) 0,600 <r< 0,699, associação fraca; e e) $r<0,600$, associação desprezível.

Entretanto, para que haja evidência suficiente para apoiar a existência de associação significativa, é necessário que o valor do coeficiente de correlação de Pearson seja superior a um valor crítico que varia em função do tamanho da amostra. Usando a expressão dada por Costa Neto (2002, p. 184) e considerando nível de significância de $5 \%$ e amostra de oito elementos, o valor crítico do coeficiente de correlação é 0,707 . Ou seja, para valores de $r<0,707$, não há evidência suficiente para apoiar a existência de associação significativa entre essas variáveis, ou, nas palavras de Costa Neto, pode-se concluir que não existe realmente correlação linear entre as variáveis.

O Quadro 3 apresenta os resultados dos testes das hipóteses. 
Quadro 3 - Resultado dos testes das hipóteses sobre a influência das variáveis do CAC-Redes na competitividade das empresas

Hipótese específica 1: O foco das armas e vínculos da competição nos campos da competição e coadjuvantes eleitos pela empresa tem forte influência na sua competitividade em relação às empresas concorrentes. Hipótese especifica 2: A dispersão das armas e vínculos da competição nos campos da competição e coadjuvantes eleitos pela empresa não influencia sua competitividade em relação às empresas concorrentes.

Hipótese especifica 3: A intensidade média das armas e vínculos da competição da empresa tem pequena influência na sua competitividade em relação às empresas concorrentes.
Três testes de correlação foram feitos. Os valores do coeficiente de correlação linear de Pearson do grau de competitividade das vinícolas com o foco das armas $(0,866)$, com o foco dos vínculos $(0,965)$ e com o foco das armas e vínculos $(0,927)$ evidenciam, respectivamente, associação forte, muito forte e muito forte.

Por esses três testes, a hipótese específica 1 foi confirmada.

Três testes de correlação foram feitos. Os valores do coeficiente de correlação linear de Pearson entre o grau de competitividade das vinícolas e a dispersão das armas $(0,684)$, a dispersão dos vínculos $(0,670)$ e a dispersão das armas e vínculos $(0,681)$ mostram que não há evidência suficiente para apoiar a existência de associação significativa entre essas variáveis, pois em todos $r<0,700$.

Por esses três testes, a hipótese específica 2 foi confirmada.

Três testes de correlação foram feitos. Os valores do coeficiente de correlação linear de Pearson do grau de competitividade das vinícolas com a intensidade média das armas $(0,797)$, com a intensidade média dos vínculos $(0,859)$ e com a intensidade média das armas e vínculos $(0,837)$ evidenciam, respectivamente, associação moderada, forte e forte. Apenas a coeficiente de correlação linear de Pearson do grau de competitividade das vinícolas com a intensidade média das armas confirma a hipótese específica 3.

A hipótese específica 3 foi parcialmente confirmada. Em termos estritos, a hipótese não foi confirmada.

Fonte: Autores.

Pelos resultados dos nove testes estatísticos, pode-se concluir que o foco (das armas, dos vínculos e das armas + vínculos da competição) no campo da competição eleito pela empresa explica melhor do que a intensidade média (das armas, dos vínculos e das armas + vínculos da competição) porque uma vinícola é mais competitiva que outra. Aliando aos resultados aos da dispersão, conclui-se que a hipótese geral da pesquisa foi confirmada e comprovam, provisoriamente (Popper, 2005), a tese do CAC-Redes. Este, sem dúvida, é o mais importante resultado da pesquisa, pois dá esperança sobre a futura validação do CAC-Redes.

Ou seja, os resultados são exatamente os previstos e contribuirão para a esperada validação do CAC-Redes. Como a pesquisa foi realizada de acordo com os preceitos da metodologia científica e embasada no já validado modelo de campos e armas da competição (Contador, 2008, p.127-154), não há razão para não acreditar que os resultados estejam corretos. Está aqui a principal contribuição do estudo. 
Sobre vinícolas brasileiras, a maioria no território gaúcho, a pesquisa feita em Scopus, Web of Science, Google Scholar e Scielo identificou grande variedade de temas: muitos artigos sobre redes de cooperação e internacionalização; alguns sobre capital social, competitividade da rede, competência coletiva, cadeia de valor e inovação. Os temas menos estudados são: estratégia de diferenciação, empreendedorismo, processo de clusterização, vantagem competitiva, gestão ambiental.

Como a temática desses estudos é diferente da abordada neste artigo, é impossível comparar resultados. Por outro lado, evidencia a originalidade da nossa abordagem.

Entretanto, a pesquisa bibliográfica encontrou o estudo de Oliveira (2004) realizado no cluster de São Roque também usando o CAC (Contador, 2008) como referencial teórico, o que permite comparar resultados (Tabela 3). Do universo de 13 vinícolas, esse estudo pesquisou oito, pois uma não respondeu os questionários e quatro foram excluídas após análise da normalidade da amostra.

Tabela 3 - Comparação dos resultados dos testes estatísticos entre a pesquisa atual, a de 2004 e a de Contador (2008)

\begin{tabular}{|c|c|c|c|c|c|c|c|c|c|c|}
\hline & \multicolumn{4}{|c}{ Armas } & \multicolumn{3}{c|}{ Vínculos } & \multicolumn{3}{c|}{ Armas + Vínculos } \\
\hline Pesquisa & IMA & Foco & Dispersão & IMV & Foco & Dispersão & IM(A+V) & Foco & Dispersão \\
\hline $\begin{array}{c}\text { Atual } \\
\text { Oliveira } \\
\text { (2004) }\end{array}$ & 0,787 & 0,866 & 0,684 & 0,859 & 0,965 & 0,670 & 0,837 & 0,927 & 0,681 \\
\hline $\begin{array}{c}\text { Contador } \\
\text { (2008) }\end{array}$ & 0,669 & 0,849 & 0,642 & 0,295 & 0,390 & 0,403 & 0,778 & 0,894 & 0,409 \\
\hline
\end{tabular}

Fonte: Autores.

A pesquisa de Oliveira (2004), além das armas da competição, considerou apenas vínculos de cooperação (na atual, confiança, comprometimento e cooperação). Os resultados de ambas as pesquisas são bastante semelhantes (Tabela 3). Quanto à correlação de armas e armas + vínculos com o GC, segundo recomendação de Costa Neto: a) há associação muito forte ou forte com o foco e forte ou moderada com a intensidade média; b) o coeficiente de correlação com o foco é sempre maior do que com a intensidade média; c) não há associação com a dispersão.

Entretanto, quanto aos vínculos, há discrepância: a pesquisa de 2004 não encontrou associação entre foco ou intensidade média com GC, e a atual, sim. Mas não encontrar associação com cooperação torna questionável o resultado da pesquisa de 2004, pois são inúmeros os estudos que atribuem vantagem competitiva à cooperação.

Deve-se também comparar os resultados do estudo atual com a média das pesquisas realizadas por Contador (2008, p.140) em 176 empresas de variados segmentos econômicos que validaram o CAC e trataram portanto apenas de armas da competição. Pela Tabela 3, há correlação forte do foco das armas com o GC. Apesar dos valores distantes para as duas outras correlações, a conclusão é idêntica: 
não há associação da dispersão com o GC, e o foco explica melhor a competitividade do que a intensidade média das armas. Resultados próximos aos da pesquisa atual são os do estudo de Contador (2008, p.140) sobre serviços de assistência técnica de aparelhos domésticos.

\section{Conclusão}

Contador (2008) concebeu, desenvolveu e validou o modelo de campos e armas da competição (CAC), modelo qualiquantitativo que representa como as empresas concorrentes competem e que é o mais completo modelo de formulação de estratégia entre os 15 existentes (Satyro et al., 2017). Agora, Contador (2018) está desenvolvendo um novo modelo qualiquantitativo, o de campos e armas da competição aplicado a redes de negócio (CAC-Redes), que é uma extensão do CAC e se fundamenta em três perspectivas: Visão Baseada na Indústria, RBV e Visão Relacional. O objetivo deste artigo é apresentar ineditamente a concepção deste novo modelo. Para avaliar sua consistência e contribuir para seu desenvolvimento e futura validação, foi realizada uma pesquisa empírica no cluster vitivinicultor de São Roque, cujos resultados estão apresentados.

O CAC-Redes centra-se no problema da pesquisa: Qual a influência das competências organizacionais e dos vínculos sociais na competitividade das empresas que operam numa rede de negócio?, cuja hipótese geral é: Numa rede de negócio, quanto maior a intensidade das competências de uma empresa e dos vínculos sociais que estabelece com as empresas concorrentes, maior sua competitividade em relação às concorrentes. Esta hipótese geral foi confirmada por meio de três hipóteses específicas, verificadas por nove testes estatísticos.

Pelo CAC-Redes (Contador, 2018): a) a competitividade das empresas é mensurada pela variável quantitativa grau de competitividade; b) as competências organizacionais são representadas pelas armas da competição e sua intensidade; e c) as relações sociais entre as empresas da rede, pelos vínculos de confiança, comprometimento e cooperação.

Na pesquisa empírica, para verificar a influência das competências organizacionais e dos vínculos sociais na competitividade das empresas, formulou-se a hipótese geral: Na rede de vitivinicultura de São Roque, quanto maior a intensidade das armas relevantes e quanto maior a intensidade dos vínculos sociais relevantes, maior sua competitividade em relação às concorrentes. Nove testes de correlação verificaram as três hipóteses específicas que sustentam a hipótese geral, confirmando-a como mostrado abaixo.

A comprovação da hipótese específica 1 confirmou que a variável "foco das armas e vínculos nos campos da competição e coadjuvantes eleitos pela empresa para competir" explica a competitividade das vinícolas, pois a pesquisa constatou que o coeficiente de correlação linear de Pearson ( $r$ ) entre essa variável e o grau de competitividade das empresas (GC) foi 0,927, evidenciando 
associação muito forte. Ou seja, o foco das armas e vínculos explica $86 \%\left(r^{2}\right.$ - valor do coeficiente de explicação) da competitividade das vinícolas pesquisadas. Esse resultado confirma o das pesquisas empíricas realizadas por Contador (2008, p.139) em 176 empresas de variados segmentos econômicos: o "foco das armas nos campos da competição e coadjuvantes eleitos pela empresa para competir" explica, na média das pesquisas, $79 \%\left(r^{2}\right)$ da competitividade delas, sendo, portanto, a variável que explicita a razão de uma empresa ser mais competitiva que outra.

O CAC-Redes (Contador, 2018), analogamente ao CAC (Contador, 2008), possui duas variáveis que servem de contraprova ao foco, quais sejam, dispersão e intensidade média. De fato, os valores do coeficiente de correlação linear de Pearson (Tabela 2 e Quadro 3) mostram que: a) a dispersão das armas e vínculos não influencia a competitividade (hipótese específica 2); e b) a intensidade média das armas e vínculos tem menor influência que o foco das armas e vínculos (hipótese específica 3).

Os resultados das correlações confirmam a hipótese geral (quanto maior a intensidade das armas relevantes e quanto maior a intensidade dos vínculos sociais relevantes, maior sua competitividade em relação às concorrentes), porque o foco das armas e vínculos é calculado pelo quociente entre a soma da intensidade das armas e vínculos relevantes e a soma da intensidade máxima possível de ser obtida em tais armas e vínculos, como exposto na Seção 3.

Assim, a pesquisa constatou a influência das competências organizacionais e dos vínculos sociais de confiança, comprometimento e cooperação na competitividade das vinícolas, desde que competências e vínculos estejam alinhados aos campos escolhidos pelas empresas para competir, comprovando a tese do CAC-Redes, pois o foco das armas e vínculos é a variável que expressa esse alinhamento. Este resultado é a principal contribuição do estudo.

Os resultados da pesquisa são exatamente os previstos e contribuirão para a esperada validação do CAC-Redes. Como a pesquisa foi realizada conforme os preceitos da metodologia científica e embasada no já validado modelo de campos e armas da competição (Contador, 2008, p.127-154), não há razão para não acreditar que os resultados estejam corretos.

Face aos resultados da pesquisa, é possível responder as quatro questões colocadas na Introdução, que motivaram a pesquisa e são fundamentais para o desenvolvimento do CAC-Redes. Especificamente em relação ao cluster de São Roque:

a) As competências das vinícolas influenciam sua competitividade? Sim, desde que estejam alinhadas aos campos da competição eleitos por elas, pois o coeficiente de correlação linear de Pearson entre o foco das armas e o grau de competitividade delas (GC) é r =0,866 (Tabela 2), evidenciando associação positiva forte;

b) Os vínculos sociais das vinícolas com outros atores da rede influenciam sua competitividade? Sim, desde que estejam alinhados aos campos da competição eleitos por elas, pois o 
coeficiente de correlação linear entre o foco dos vínculos e o GC é $r=0,965$ (Tabela 2), evidenciando associação positiva muito forte;

c) Apenas coopetição (competição e cooperação) é suficiente para ampliar a competitividade? Sim, mas se forem consideradas armas da competição juntamente com vínculos de confiança, comprometimento e cooperação, o efeito na competitividade seria maior, pois há associação positiva muito forte $(r=0,927$ - Tabela 2$)$ entre o foco das armas e vínculos e $o$ GC; e

d) Quais vínculos sociais influenciam a competitividade? Os vínculos de confiança, comprometimento e cooperação influenciam fortemente a competitividade ( $r=0,965$ Tabela 2), entretanto não se pode afirmar se outros tipos de vínculos sociais exerceriam influência.

A principal contribuição da pesquisa foi constatar a influência das competências organizacionais e dos vínculos sociais na competitividade das vinícolas, desde que competências e vínculos estejam alinhados aos campos escolhidos pelas empresas para competir.

Assim, a pesquisa cumpriu seu objetivo ao contribuir teoricamente para o desenvolvimento e futura validação do CAC-Redes (Contador, 2018), pois constatou que ele permite:

a) Entender de forma bastante ampla a competição intracluster;

b) Analisar eficazmente a influência simultânea na competitividade empresarial dos vínculos sociais e competências;

c) Analisar conjuntamente os vínculos de confiança, comprometimento e cooperação;

d) Confirmar preliminarmente que o CAC-Redes consegue representar como as empresas inseridas numa rede de negócio competem e como podem aumentar sua competitividade.

A pesquisa contribuiu teoricamente para a abordagem de vantagens competitivas em rede de negócio ao suprir as seguintes lacunas encontradas na literatura:

a) Comprovou, pela primeira vez, que competências (armas) e vínculos considerados simultaneamente influenciam fortemente a competitividade das empresas $(r=0,927)$;

b) Comprovou que vínculos sociais de confiança, comprometimento e cooperação influenciam fortemente a competitividade das empresas $(r=0,965)$;

c) Comprovou que vínculos sociais potencializam a influência das competências na competitividade empresarial, pois o coeficiente de correlação de armas e vínculos com grau 
de competitividade $(r=0,927)$ foi maior que o coeficiente entre armas e grau de competitividade $(r=0,866)$.

d) Comprovou, pela primeira vez, que considerar simultaneamente competências e vínculos proporciona uma abordagem mais geral do que a Visão Relacional de Dyer e Singh (1998; 2018);

e) Comprovou que vínculos sociais devem ser considerados conjuntamente com competências na formulação da estratégia competitiva e integrar os objetivos estratégicos da empresa.

Como contribuição gerencial, a pesquisa permite recomendar aos empresários vinhateiros:

a) Escolham campos da competição e coadjuvantes considerando simultaneamente as preferências dos clientes e a posição competitiva dos concorrentes, usando a proposta de Contador (2008, p.375-387);

b) Aperfeiçoem ao máximo apenas as armas e vínculos relevantes (os alinhados ao campo da competição e coadjuvantes) utilizando a metodologia de Contador (2008, p.399-404);

c) Fortaleçam os laços de confiança, comprometimento e cooperação com as concorrentes;

d) Estreitem e aperfeiçoem as relações com fornecedores, inclusive fazendo compras em conjunto com outras vinícolas;

e) Invistam em ações que possam aumentar o fluxo de turistas na região;

f) Busquem parcerias com órgãos governamentais e empresas privadas;

g) Utilizem o SINDUSVINHO (Sindicato das Indústrias Produtoras de Vinho de São Roque) para reduzir as disparidades tecnológicas existentes.

A originalidade da nossa abordagem é evidenciada pelo fato de ser diferente daquelas dos estudos encontrados na literatura.

Como a pesquisa empírica se ateve às vinícolas de São Roque, seus resultados não podem ser generalizados para a agroindústria vinícola, nem para outras redes de negócio.

Para estudos futuros, recomendam-se: a) aplicar esta metodologia a outros clusters e redes para verificar a aplicabilidade do CAC-Redes; b) pesquisar a influência na competitividade empresarial de cada vínculo econômico, social e locacional, individualmente e conjuntamente, concomitantemente ou não com armas da competição.

\section{Referências}

Bain, J. (1968). Industrial Organization. New York: John Wiley and Sons.

Balestrin, A., Verschoore, J.R. \& Perucia, A. (2014). A visão relacional da estratégia: evidências empíricas em redes de cooperação empresarial. Revista Base (UNISINOS), 11 (1), 47-58 
Barney, J., Wright, M., \& Ketchen Jr, D. J. (2001). The resource-based view of the firm: Ten years after 1991. Journal of Management, 27(6), 625-641.

Bengtsson, M., \& Kock, S. (1999). Cooperation and competition in relationships between competitors in business networks. Journal of Business \& Industrial Marketing, 14(3), 178-194.

Boyd, N.G., Lado, A.A., \& Hanlon, S.C. (1997). Competition, cooperation and the search for economics rents: a syncretic model. Academy of Management Review, 1, p. 110-141.

Caves, R. E., \& Porter, M. E. (1977). From entry barriers to mobility barriers: Conjectural decisions and contrived deterrence to new competition. Quarterly Journal of Economics, 91(2), 241-261.

Contador, J.C. (2008). Campos e Armas da Competição. São Paulo: Saint Paul.

Contador, J.C. (2008). Concepção do CAC-Redes. UNIP, Mimeo.

Costa Neto, P.L.O. (2002). Estatística. Sao Paulo: Edgard Blucher.

Dyer, J. H., \& Singh, H. (1998). The Relational View: Cooperative Strategy and Sources of Interorganizational Competitive Advantage. Academy of Management Review, 23(4), 660-679.

Dyer, J. H., Singh, H., \& Hesterly, W. S. (2018). The relational view revisited: A dynamic perspective on value creation and value capture. Strategic Management Journal, 39(12), 3140-3162.

Fonseca, J. J. S. (2002). Metodologia da pesquisa científica. Fortaleza: UEC, 2002.

Furrer, O., Thomas, H., \& Goussevskaia, A. (2008). The structure and evolution of the strategic management field: A content analysis of 26 years of strategic management research. International Journal of Management Reviews, 10(1), 1-23.

Garcia-Pont, C. \& Nohria N. (2002). Local versus global mimetism: The dynamics of alliance formation in the automobile industry. Strategic Management Journal. Feb. https://doi.org/10.1002/smj.225.

Gulati, R. (1995). Does familiarity breed trust? The implications of repeated ties for contractual choices. The Academy of Management Journal, 38(1), 85-112.

Gulati, R., \& Lawrence P. (1997). Organizing vertical networks: A design perspective. Paper presented at the Academy of Management Annual Meeting, Boston, MA.

Gulati, R., Nohria, N., \& Zaheer, A. (2000). Strategic Networks. Strategic Management Journal, 21, 203-215.

Hoffmann, V.; Belussi, F.; Martinéz-Fernadéz, M.; Reyes JR, E. (2017). United we stand, divided we fall? Clustered firms' relationships after the 2008 crisis. Entrepreneurship \& Regional Development 1(24).

Hoopes, D. G., Madsen, T. L., \& Walker, G. (2003). Guest editor's introduction to the special Issue: Why is there a resource-based view. Strategic Management Journal, 24(10), 889-902.

Jarillo, J.C. (1988). On Strategic Networks. Strategic Management Journal, 9(1), 31-41.

La Porta, R., Lopez-De-Silanes, F., Shleifer, A. \& Vishny, R. (1997). Trust in Large Organizations. American Economic Review, 87, 333- 338. 
Lee, H., Kim, M. S. \& Kim, K. K. (2014). Interorganizational information systems visibility and supply chain performance. International Journal of Information Management, 34 (2), 285-295.

Marconi, M. \& Lakatos, E. (2003). Fundamentos de metodologia científica. 5 ed. São Paulo: Atlas.

Marshall, A. (1982). Princípios de economia: tratado introdutório. São Paulo: Abril Cultural, v. I.

Martins, G. S., Rossoni, L., Duarte, A. L. C. M. \& Martins, R. S. (2017). Supply chain relationships: exploring the effects of both relational and structural embeddedness on operational performance. International Journal of Procurement Management, 10 (5), 639-664.

Moreira, D. A. (2002). O método fenomenológico na pesquisa. São Paulo, SP: Pioneira Thomson.

Nalebuff, B. \& Bradenburger, A. (1997). Co-opetition: competitive and cooperative business strategies for the digital economy. Strategy \& Leadership, 25(6), 28-35.

Oliveira, I. V. de (2004). Cluster como estratégia competitiva para a indústria vinícola: Análise da competitividade por meio de campos e armas da competição. Diss. de Mestrado (Administração). UNINOVE, São Paulo.

Popper, K. R. (2005). The Logic of Scientific Discovery. London and New York: Routledge.

Porter, M.E. (1980). Competitive strategy. New York: Free Press, 1980.

Porter, M.E. (1985). Competitive advantage. New York: Free Press.

Porter, M.E. (1990). The Competitive Advantage of Nations. New York: Free Press.

Porter, M.E. (1996), "What is Strategy?" Harvard Business Review, 74(6), 61-78.

Porter, M.E. (1998). Clusters and the new economics of competition. Harvard Business Review, 76 (6), 77.

Porter, M.E. (1999). Cluster e Competitividade. H.S.M. Management, 3(15), 100-110, Jul./Ago.

Ramos-Rodríguez, A.; Ruíz-Navarro, J. (2004). Changes in the intellectual structure of strategic management research: A bibliometric study of the Strategic Management Journal, 1980-2000, Strategic Management Journal, 25(10), 981-1004.

Richardson, G.B. (1972). The organization of industry. Economic Journal, 82, 883-896.

Rosenfeld, S.A. (1996). Does cooperation enhance competitiveness? Assessing the impacts of interfirm collaboration. Research Policy, 25(2), 247-263.

Satyro, W, Sacomano, J. B., Contador, J. C., Almeida, C. A, \& Giannetti, B. F. (2017). Process of strategy formulation for sustainable environmental development: basic model. Journal of Cleaner Production, 166, 1295-1304.

Shapiro, D.L., Sheppard, B.H., \& Cheraskin, L. (1992). Business on a handshake. Negotiation Journal, 365-377. 
Tsai, W. (2002). Social structure of coopetition within a multiunit organization: coordination, competition, and intra organizational knowledge sharing. Organizational Science, 13(2), 179-190.

Wang, Y. \& Rajagopalan, N. (2015). Alliance capabilities: review and research agenda. Journal of Management, 41 (1), 236-260.

Williamson, O. (1981). The Economics of Organization: The Transaction Cost Approach. American Journal of Sociology, 87(3), 548-577.

Zaccarelli, S.B., Dutra, I.S., \& Santos, S.A. (2008). As redes empresariais de negócios e o seu poder competitivo: racionalidade lógica ou estratégica? Revista de Negócios, 13(1), 11-27.

Zaheer, A., \& Zaheer S. (1999). The structure of global competition: A network approach. Paper presented at the SMJ Special Issue Conference, Northwestern University.

Zhang L. \& Wang, J. (2018) Research on the relationship between relational capital and relational rent. Cogent Economics \& Finance, 6 (1431091), 1-18.

Zonta, P., Molozzi, G.; Jentz, J; Carvalho, C. (2015). Relação entre cooperação e aprendizado organizacional com a competitividade em uma rede interorganizacional. Redes, 20(1), 179-193. 